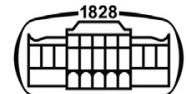

AKADÉMIAI KIADÓ

Acta Chromatographica

33 (2021) 2, 195-201

DOI:

$10.1556 / 1326.2020 .00684$

(c) 2020 The Authors

ORIGINAL RESEARCH

PAPER

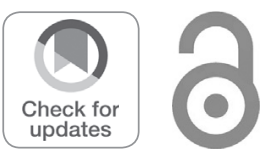

\section{Analysis of gallic acid and ellagic acid in leaves of Elaeagnus angustifolia L. from different habitats and times in Xinjiang by HPLC with cluster analysis}

YUN SUN ${ }^{1}$, JIAJIA LIU ${ }^{1}$, BAYERTAI $^{1}$, SHASHA TANG ${ }^{1}$ and XIAOYING $\mathrm{ZHOU}^{2 *}$ (1)

\author{
${ }^{1}$ College of Traditional Chinese Medicine, Xinjiang Medical University, Ürümqi, Xinjiang, China \\ ${ }^{2}$ School of Pharmacy, Xinjiang Medical University, Ürümqi, Xinjiang, China
}

Received: July 22, 2019 • Accepted: July 30, 2019

Published online: September 9, 2020

\begin{abstract}
Objective: To determine the levels of gallic acid and ellagic acid by using high-performance liquid chromatography (HPLC) with R software hierarchical cluster analysisin Elaeagnus angustifolia L. gathered from different locations in Xinjiang. Methods: A chromatographic column Diamonsil C18 with a size of $4.6 \times 250 \mathrm{~mm}$ and $5 \mu \mathrm{m}$ was used with methanol as $\mathrm{A}$ and $0.1 \%$ phosphoric acid aqueous solution as $\mathrm{B}$ as the mobile phase. The flow rate was $1 \mathrm{~mL} / \mathrm{min}$ for the gradient elution and the injection volume was $5 \mu \mathrm{L}$. HPLC was performed with a detection wavelength of $260 \mathrm{~nm}$ and chromatographic column of $35^{\circ} \mathrm{C}$. In addition, R software hierarchical clustering method was used for studying the levels of gallic acid and ellagic acid in E. angustifolia L. from 10 areas. Results: Gallic acid and ellagic acid showed a good linear relationship between 7.375 and $236 \mu \mathrm{g} / \mathrm{mL}$ with a correlation coefficient of 0.9999 , and between 3.625 and $116 \mu \mathrm{g} / \mathrm{mL}$ with a correlation coefficient of 0.9999 respectively. The average recovery values were 103.98 and $101.57 \%$, and the Relative Standard Deviation (RSD) values were 1.92 and $1.47 \%$. Conclusion: Differences in the levels of gallic acid and ellagic acid in E. angustifolia L. leaves from different areas in Xinjiang showed that both were the highest in Kuitun.
\end{abstract}

\section{KEYWORDS}

Elaeagnus angustifolia L. leaves, gallic acid, ellagic acid, HPLC, cluster analysis

\section{INTRODUCTION}

Elaeagnus angustifolia L. belongs to the genus Elaeagnus of the Elaeagnaceae family and is also called fragrant willow, cinnamon willow, silver willow, and Qi Lixiang; it is widely distributed in cold and arid Asia, temperate zones of Europe, and parts of North America [1]. The branches, leaves, flowers, and fruits of E. angustifolia L. have high economic value and are known as the "treasure tree" of saline-alkali land [2]. Different parts of E. angustifolia have been used in pharmaceutics, the perfume industry, and wood production. According to the "Chinese Herbal Medicine" [2], the leaves of E. angustifolia are spicy, astringent. It clears heat and has detoxifying, antibacterial, and anti-inflammatory effects, and promotes blood circulation and stops bleeding; additionally, the leaves are usedfor bacterial dysentery, enteritis diarrhea, chronic bronchitis, and coronary heart disease [3-5]. The leaves of E. angustifolia contain various flavonoids, organic acids, and tannins, as well as 8 amino acids that are not synthesized by animals [6]; additionally, the leaves have a high market economy value. The extract of E. angustifolia L. has good antioxidant and bacteriostatic effects [7-8].

Preliminary activity screening study of the research group [9, 15-17] showed that the extracts of ethyl acetate, $n$-butanol, and water from the leaves of E. angustifolia L. have 
inhibitory effects on $\alpha$-glucosidase activity. In the early stage of this research, we found that the leaves of E. angustifolia L. contained phenolic acids, such as ellagic acid, gallic acid, and ferulic acid.

Compared with some traditional folk medicines, the leaves of E. angustifolia L. have many unknown problems to be solved, for example, their active ingredients are not completely clear They are used as medicine in some folk remedies, but the leaves of E. angustifolia L. are not widely used and have not been included in the Chinese Pharmacopoeia. It is only included in some standards, such as Uyghur Medicine and Chinese Herbal Medicine. Moreover, only a few studies have been conducted on the chemical constituents of phenolic acids in the leaves, and research has mostly concentrated on the flavonoids. What's more, the leaves of this plant species from different places have different forms, and the contents of various components vary. Hence, rigorous and scientific quality standards and basic research need to be done.

In this study, high-performance liquid chromatography (HPLC) was used to determine the contents of gallic acid and ellagic acid in the antioxidant-active parts of E. angustifolia L. leaves at different dates and from different origins in Xinjiang. In this work, $\mathrm{R}$ software hierarchical clustering analysis method was used. The analysis and comparison of the components in the leaves provide highly scientific theoretical basis for the use, promotion, and rational interpretation of E. angustifolia L. leaves.

\section{EXPERIMENT}

\section{Instrument agilent}

1220 LC High Performance Liquid Chromatograph (Agilent UV Detector, Binary Pump), Diamonsil C18 (4.6 × $250 \mathrm{~mm}$, $5 \mu \mathrm{m})$, XS105 Electronic Balance (Mettler, Germany) Toledo Instrument Co., Ltd.), KQ-5200DE CNC ultrasonic cleaning instrument (Kunshan Ultrasonic Instrument Co., Ltd.).

\section{Materials and reagents}

Gallic acid (MUST-15042910, quality score 99.04\%, Chengdu Manster Biotechnology Co., Ltd.); ellagic acid (111959-201602, mass fraction 89.3\%, China Institute of Food and Drug Verification); methanol is chromatographically pure, (Fisher and analytical grade in the United States), phosphoric acid is pure grade, diethyl ether is analytically pure, and water is ultrapure water. 10 batches of the leaves of E. angustifolia L. were collected from different origins and seven batches were collected from different months. The specific dates and places are shown in Tables 1 and 2. After being collecting, leaves are dried and ready for use. The identification by Associate Professor Xu Haiyan from the College of Traditional Chinese Medicine of Xinjiang Medical University is the dry leaves of the genus Elaeagnus of Elaeagnaceae.
Table 1. The resource of Elaeagnus angustifolia L. leaf of different origin

\begin{tabular}{lcc}
\hline $\begin{array}{l}\text { Material } \\
\text { numbers }\end{array}$ & Collection dates & Places of origin \\
\hline 1 & August 26, 2015 & Yining, Xinjiang \\
2 & September 07, 2015 & Kashi, Xinjinag \\
3 & August 02, 2015 & Hami, Xinjinag \\
4 & August 14, 2015 & Kuitun, Xinjinag \\
5 & July 05, 2015 & Urumqi Carp \\
& & Mountain, Xinjiang \\
6 & August 12, 2015 & Balikun Santang Lake, \\
& & Xinjiang \\
7 & August 20, 2017 & Aksu Shaya, Xinjiang \\
8 & August 22, 2015 & Kelamayi White \\
& & Alka Beach, Xinjiang \\
9 & September 04, 2015 & Wushtala Township, \\
& & Heshuo, Xinjinag \\
10 & June 30, 2015 & Turpan Desert \\
& & Botanical Garden, \\
& & Xinjiang \\
\hline
\end{tabular}

Table 2. The resource of Elaeagnus angustifolia L. leaf in different months

\begin{tabular}{lcc}
\hline $\begin{array}{l}\text { Material } \\
\text { numbers }\end{array}$ & Collection dates & Places of origin \\
\hline May & May 12, 2017 & $\begin{array}{c}\text { Urumqi Carp Mountain, } \\
\text { Xinjiang }\end{array}$ \\
Jun & June 15, 2017 & $\begin{array}{c}\text { Urumqi Carp Mountain, } \\
\text { Xinjiang }\end{array}$ \\
Jul. & July 18, 2017 & $\begin{array}{c}\text { Urumqi Carp Mountain, } \\
\text { Xinjiang }\end{array}$ \\
Aug. & August 14, 2017 & $\begin{array}{c}\text { Urumqi Carp Mountain, } \\
\text { Xinjiang }\end{array}$ \\
Sept. & September 15, 2017 & $\begin{array}{c}\text { Urumqi Carp Mountain, } \\
\text { Xinjiang }\end{array}$ \\
Oct. & October 13, 2017 & $\begin{array}{c}\text { Urumqi Carp Mountain, } \\
\text { Xinjiang }\end{array}$ \\
Nov. & November 14, 2015 & Urumqi Carp Mountain, \\
& & Xinjiang \\
\hline
\end{tabular}

\section{Methods}

Preparation of standard solution. Gallic acid (10.72 mg) and ellagic acid $(2.91 \mathrm{mg})$ were weighed accurately and placed them in a $10 \mathrm{~mL}$ flask. The acids were dissolved with methanol to a constant volume and then shaken. The standard solution was reserved for the next experiment.

Preparation of sample solution. Dried leaves weighing $100 \mathrm{~g}$ were soaked overnight with petroleum ether and dried. Afterward, continuous reflux extraction was done with ethyl acetate for $6 \mathrm{~h}$ and dried. Water was used for continuous reflux extraction, with material ratios of 1:12 and 1:10 and extraction periods of 2 and $1.5 \mathrm{~h}$, respectively. The combined filtrate was concentrated and dried to a powder at $60{ }^{\circ} \mathrm{C}$ and then reserved.

The powder was weighed to $5.0 \mathrm{~g}$ and was placed in a 100 $\mathrm{mL}$ corked conical bottle. Heating reflux extraction was performed with $40 \mathrm{~mL}$ distilled water for $1 \mathrm{~h}$, and then the sample 
was filtered. The filtrate was extracted twice by using $40 \mathrm{~mL}$ ether each time, and then combined with ether solution and volatized to dryness. The residue was dissolved in methanol and the volume was fixed in a $10 \mathrm{~mL}$ volumetric flask as the original solution. Afterward, $2.5 \mathrm{~mL}$ solution from original solution was absorbed and placed it in $10 \mathrm{~mL}$ volumetric bottle, adding methanol to the scale. The sample solution was obtained by filtration with a microporous filter membrane $(0.22 \mu \mathrm{m})$.

Chromatographic condition. The chromatographic column was Diamonsil C18 column $(4.6 \times 250 \mathrm{~mm}, 5 \mu \mathrm{m})$; the mobile phase was methanol (A) with $0.1 \%$ phosphoric acid solution (B), gradient elution ( $0-8 \mathrm{~min}, 90 \rightarrow 80 \% \mathrm{~B}$; $8-30 \mathrm{~min}, 80 \rightarrow 55 \% \mathrm{~B}$; 30-60 $\mathrm{min}, 55 \rightarrow 30 \% \mathrm{~B}$ ); flow rate was $1 \mathrm{~mL} / \mathrm{min}$, injection volume $5 \mu \mathrm{L}$, detection wavelength $260 \mathrm{~nm}$, temperature $35^{\circ} \mathrm{C}$.

Specificity test and system suitability test. Under the chromatography condition, the theoretical tray number of gallic acid and ellagic acid exceeded 2,000, and the separation degree from adjacent peaks exceeded 1.5. The HPLC chromatogram and the UV absorption spectra of peak are shown in Figs 1 and 2, respectively.

\section{RESULTS AND DISCUSSION}

\section{Linear relationship}

The standard solution gallic acid was absorbed precisely 65 , 125, 250, 500, 1,000 and 2,000 $\mu \mathrm{L}$, and ellagic acid was
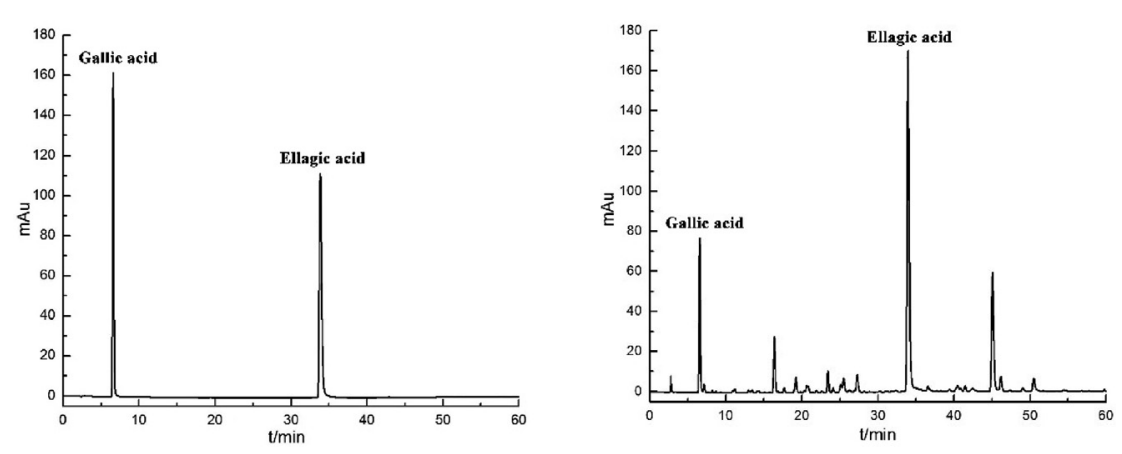

(A)(B)

Fig. 1. HPLC chromatogram of mixed control (A) and water extract from Elaeagnus angustifolia L. leaf (B)
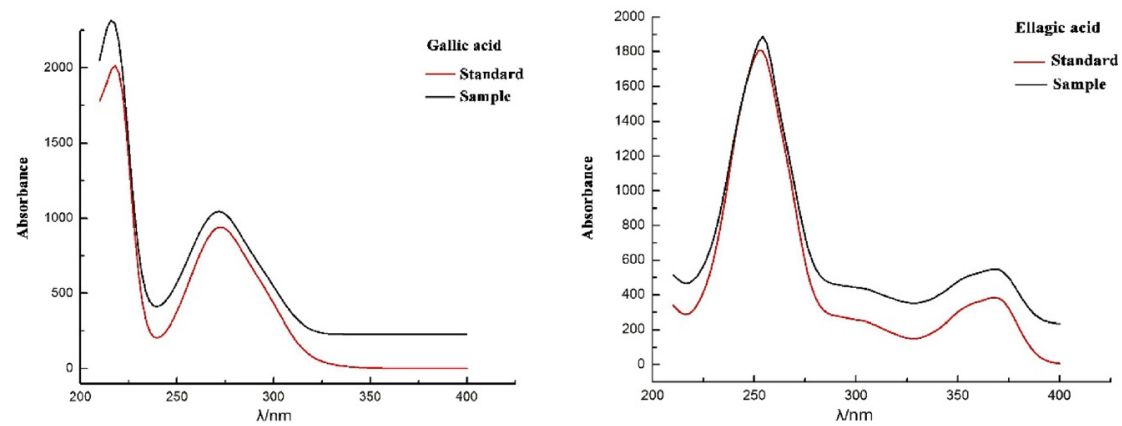

Fig. 2. Light spectra of each peak in the Elaeagnus angustifolia L. leaf water extract and Reference substance was obtained. The results showed a good linear relationship ellagic acid. The results were shown in Table 3.

\section{Precision}

Table 3. Linear inspection results

absorbed $125,250,500,1,000,2,000$, and $4,000 \mu \mathrm{L}$, then placed them in $10 \mathrm{~mL}$ volumetric flask respectively and constant volume was maintained by using methanol. The volume of the sample was $5 \mu \mathrm{L}$, and the peak area was determined according to the term chromatography condition. The standard curve was drawn with the concentration and peak area as the abscissas and ordinates, respectively, and the regression equation between the concentrations and peak area of gallic acid and

The standard solution gallic acid and ellagic acid were accurately measured, respectively, and sampling was repeated 6 times according to the term chromatography condition. Determination of peak area and calculation of Relative Standard Deviation (RSD) were performed. The RSD values of gallic acid and ellagic acid were 1.44 and

\begin{tabular}{cccc}
\hline Standard & Regression equations & $r$ & $\begin{array}{c}\text { Linearity range } \\
(\mu \mathrm{g} / \mathrm{mL})\end{array}$ \\
\hline Gallic acid & $\mathrm{Y}=266373.50 \mathrm{X}-$ & 0.9999 & $7.375-236$ \\
& 130649.81 \\
Ellagic acid & $\mathrm{Y}=753269.81 \mathrm{X}-$ & 0.9999 & $3.625-116$ \\
& 2085377.99 & & \\
\hline
\end{tabular}


Table 4. Results of recovery test of the Elaeagnus angustifolia L. leaf water extract $(n=6)$

\begin{tabular}{|c|c|c|c|c|c|c|}
\hline Compound & $\begin{array}{c}\text { Amount of sample } \\
\text { taken }(\mu \mathrm{g})\end{array}$ & $\begin{array}{c}\text { Amount of standard } \\
\text { taken }(\mu \mathrm{g})\end{array}$ & $\begin{array}{l}\text { Amount found } \\
(\mu \mathrm{g})\end{array}$ & $\begin{array}{l}\text { Recovery } \\
(\%)\end{array}$ & $\begin{array}{l}\text { Average } \\
(\%)\end{array}$ & $\begin{array}{l}\text { RSD } \\
(\%)\end{array}$ \\
\hline \multirow[t]{6}{*}{ Gallic acid } & 28.01 & 28.01 & 57.74 & 105.80 & $103.98 \pm 1.52$ & $1.92 \%$ \\
\hline & 27.98 & 28.01 & 57.85 & 106.30 & & \\
\hline & 27.97 & 28.01 & 57.53 & 105.20 & & \\
\hline & 27.95 & 28.01 & 56.67 & 102.20 & & \\
\hline & 27.92 & 28.01 & 56.72 & 102.50 & & \\
\hline & 27.95 & 28.01 & 56.58 & 101.90 & & \\
\hline \multirow[t]{6}{*}{ Ellagic acid } & 43.72 & 49.80 & 93.11 & 99.18 & $101.57 \pm 1.49$ & $1.47 \%$ \\
\hline & 43.62 & 49.80 & 94.09 & 101.35 & & \\
\hline & 43.43 & 49.80 & 94.24 & 102.03 & & \\
\hline & 43.22 & 49.80 & 93.87 & 101.71 & & \\
\hline & 43.18 & 49.80 & 93.64 & 101.33 & & \\
\hline & 43.22 & 49.80 & 94.92 & 103.82 & & \\
\hline
\end{tabular}

$1.54 \%$, respectively, and these values showed good precision of the instruments.

\section{Stability}

The sample solutions (Kuitun, 20150814) were injected in 5 $\mu \mathrm{L}$ amounts at $0,2,4,6,8,10,12$, and $24 \mathrm{~h}$. The peak area was then recorded. The RSD values of gallic acid and tannin were 0.18 and $0.58 \%$, respectively, and these values showed that the sample solution was stable within $24 \mathrm{~h}$.

\section{Repeatability}

The same batch of materials was accurately weighed 6 samples and prepared as 6 parallel sample solutions, according to the term Preparation of sample solution. The peak areas were recorded, and the sample contents were calculated. The RSD values of gallic acid and tannin were 1.16 and $1.52 \%$, respectively, and these values showed that this method has good repeatability.

\section{Recovery rate of samples}

Six known content samples were accurately weighed to $5.0 \mathrm{~g}$ and added with $28.10 \mu \mathrm{g}$ gallic acid standard and $49.8 \mu \mathrm{g}$ ellagic acid standard. The solutions were prepared according to the term chromatography condition and determined. The recovery rate of samples was calculated and the results are shown in Table 4.

\section{Determination of content}

The sample solutions were prepared according to the term Preparation of sample solution and were respectively determined $5 \mu \mathrm{L}$ to calculate the contents of gallic acid and ellagic acid with the peak area. The results in Table 5 show that the contents of gallic acid and ellagic acid are highest in Kuitun and lowest in Urumqi and Turpan, respectively. Moreover, the contents of gallic acid and ellagic acid in the samples from Hami City and Barkun Country were different, even though these two places belong to the same area. The content of ellagic acid was 3 times higher than that of gallic acid in the sample from Kashi city, and about 2 times higher in the sample from Kuitun. Furthermore, the
Table 5. Determination of gallic acid and ellagic acid in extracts of the Elaeagnus angustifolia L. leaf water extract from different areas in Xinjiang

\begin{tabular}{lccc}
\hline \multirow{2}{*}{ Samples } & \multirow{2}{*}{$\begin{array}{c}\text { Extraction } \\
\text { ratio }(\%)\end{array}$} & \multicolumn{2}{c}{ Contents $(\mathrm{mg} / \mathrm{g})$} \\
\cline { 3 - 4 } 1 & 27.22 & Gallic acid & Ellagic acid \\
\hline 2 & 26.99 & 1.93 & 3.39 \\
3 & 26.65 & 3.63 & 5.97 \\
4 & 27.16 & 8.17 & 6.83 \\
5 & 20.85 & 1.07 & 11.13 \\
6 & 29.90 & 2.33 & 2.52 \\
7 & 26.22 & 3.28 & 5.40 \\
8 & 23.68 & 2.02 & 6.42 \\
9 & 21.84 & 2.76 & 4.83 \\
10 & 21.89 & 1.38 & 5.45 \\
\hline
\end{tabular}

Table 6. Determination of gallic acid and ellagic acid in extracts of the Elaeagnus angustifolia L. leaf water extract from different month in Xinjiang

\begin{tabular}{lccc}
\hline & & \multicolumn{2}{c}{ Contents $(\mathrm{mg} / \mathrm{g})$} \\
\cline { 3 - 4 } Samples & $\begin{array}{c}\text { Water extraction } \\
\text { rate (\%) }\end{array}$ & Gallic acid & $\begin{array}{c}\text { Ellagic } \\
\text { acid }\end{array}$ \\
\hline May & 22.35 & 0.56 & 1.29 \\
Jun & 17.66 & 0.84 & 0.93 \\
Jul. & 22.72 & 6.89 & 8.52 \\
Aug & 22.57 & 5.38 & 6.80 \\
Sept & 25.53 & 5.15 & 6.00 \\
Oct & 30.75 & 4.49 & 6.53 \\
Nov & 26.62 & 2.12 & 3.03 \\
\hline
\end{tabular}

contents of both acids were similar between samples from Hami and Shaya, Aksu. The results were shown in Table 5.

\section{Cluster analysis}

To further evaluate the samples from Xinjiang, the contents of gallic acid and ellagic acid in the leaves of E. angustifolia L. from different areas in Xinjiang were analyzed by using $R$ 


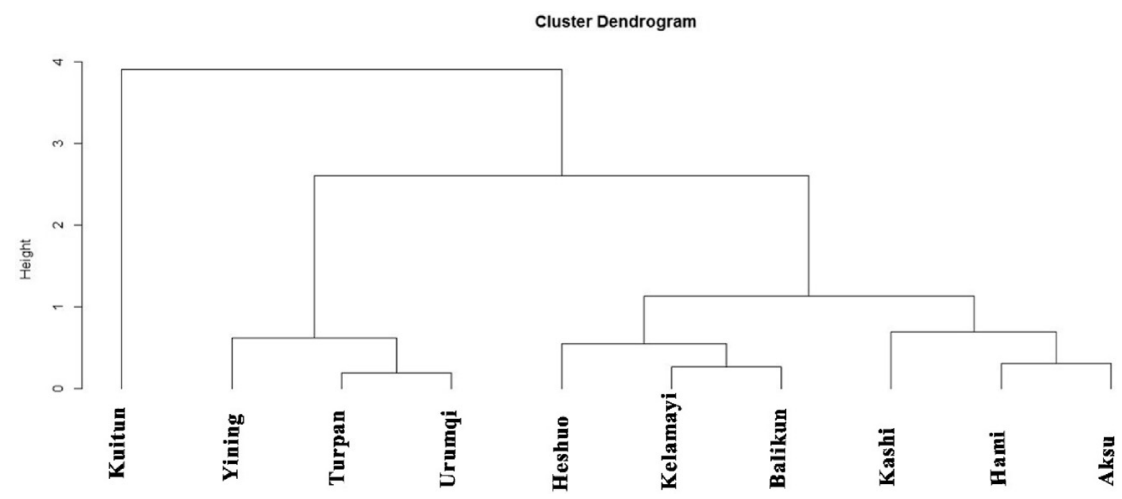

Fig. 3. HPLC-based Elaeagnus angustifolia L. leaf water extract clustering analysis

software hierarchical cluster analysis. The results in Fig. 3 show that the leaves of E. angustifolia L. from Xinjiang could be divided into three categories. The first category was in Kuitun area because the contents of gallic acid and ellagic acid were both the highest. The second category was in Yining, Turpan, and Urumqi because the contents were close to those of gallic acid and ellagic acid. Finally, other areas were automatically classified under the third category. The results showed no significant relationship between the contents of gallic acid and ellagic acid and the origins of the sample, and we could not infer whether the contents of gallic acid and ellagic acid were close to each in other nearby areas in the north and south of Xinjiang.

\section{Dynamic changes in the contents of gallic acid and ellagic acid in leaves of $E$. angustifolia $\mathrm{L}$. at different times}

Fig. 4 is the chromatogram map of the samples from different times. Fig. 5 and Table 6 show that the content of gallic acid is higher than $4 \mathrm{mg} / \mathrm{g}$ from July to October, whereas the contents in May, June, and November were lower than $2 \mathrm{mg} / \mathrm{g}$. Moreover, regular dynamic changes occurred between different months and the contents of

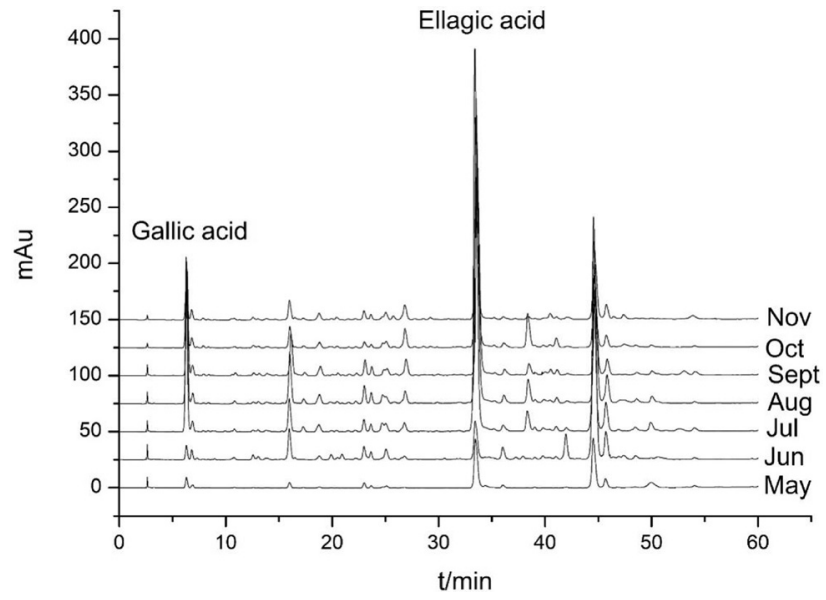

Fig. 4. HPLC chromatograms of the Elaeagnus angustifolia L. leaf water extract from different month in Xinjiang

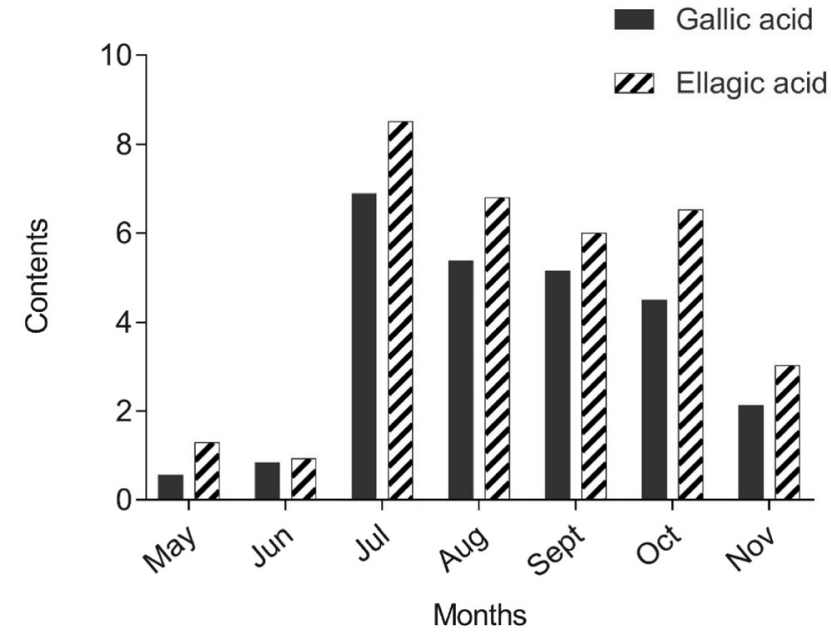

Fig. 5. Dynamic changes of gallic acid and ellagic acid in Elaeagnus angustifolia L. leaf water extract

gallic acid from May to November. The gallic acid content was the lowest in May at $0.56 \mathrm{mg} / \mathrm{g}$, after which the content gradually increased until the July content rose to the highest value, $6.89 \mathrm{mg} / \mathrm{g}$, which was 12 times that of May. The content of ellagic acid was higher than $5 \mathrm{mg} / \mathrm{g}$ from July to October, and lower than $3 \mathrm{mg} / \mathrm{g}$ at May, June, and November. The content of gallic acid in the leaves of E. angustifolia L. at different times showed regular dynamic changes among different months, and the content of gallic acid reached $8.52 \mathrm{mg} / \mathrm{g}$ in July, which was the highest, and then the content decreased gradually. However, the sudden increase in October may be related to the temperature rise in the region. The lowest content in June was $0.93 \mathrm{mg} / \mathrm{g}$, which was only $1 / 9$ that of July. The contents of gallic acid and ellagic acid in E. angustifolia L. leaves showed that the growth of plants needed to be carried out via photosynthesis. In summer, the temperature in Xinjiang is generally high and sunlight is sufficient; thus, the leaves can quickly obtain nutrients through photosynthesis. When the temperature declines in autumn, the photosynthesis is reduced secondary to less sunlight; thus, leaf nutrition becomes insufficient. Based upon the different content levels across different months, 
we can indirectly reveal that climate changes in the areas from which the samples were collected can provide clues for the rational cultivation of E. angustifolia L.

\section{RESULTS AND DISCUSSION}

\section{Determination of target components}

In the experiment, we found peaks in sample were consistent with reference targets, namely gallic acid, methyl gallate, chlorogenic acid, ellagic acid, astragalin, luteolin, kaempferol, and apigenin. To determine the true components contained in the samples, the spectrum of all components was detected according to literature [13-14] and related data. We found that astragalin can be dissolved in hot water but not in ether, apigenin is almost insoluble in water, luteolin can be dissolved in ether but only slightly soluble in hot water, and methyl gallate and chlorogenic acid can be dissolved in hot water, but the spectrums of sample and these two contents were inconsistent. Therefore, gallic acid and ellagic acid were selected as the target substances.

\section{Determination of detection wavelength}

HPLC determination of gallic acid and ellagic acid in $E$. angustifolia L. leaves were performed in this study. According to literature $[7,8]$ and structural characteristics of gallic acid and ellagic acid, gallic acid $[10,11]$ has strong absorption at 216 and $269 \mathrm{~nm}$, and ellagic acid [12] has strong absorption at 258 and $366 \mathrm{~nm}$. The absorption spectrum was measured by using a Diode Array Detector (DAD) detector, and detection wavelength was determined at $260 \mathrm{~nm}$ by analyzing the mixture and sample solution to consider the detection requirements of gallic acid and ellagic acid.

\section{Determination of the elution method}

In this experiment, HPLC method was carried out to determine the phenolic components of the water-extracted parts of E. angustifolia L. leaves. Different elution methods, such as isocratic and gradient in different proportions, were used to explore the conditions of methanol-phosphoric acid and acetonitrile-phosphoric acid. The isocratic elution could not separate the materials from the water-extracted parts of the leaves, and its peak shape was wider; whereas gradient elution was able to separate the materials, and its peaks were good. Moreover, the HPLC spectra were better in the gradient elution than in the isocratic elution. In the experiment, the changes in the phosphate buffer salt concentration had no significant effect on peak tailing. Thus, methanol and $0.1 \%$ phosphoric acid were used as the mobile phase, and the HPLC chromatogram of the components showed good peak shape and good separation effect with gradient elution method.

\section{Clustering analysis}

The contents of gallic acid and ellagic acid in the leaves of 10 batches of $E$. angustifolia L. from different regions were analyzed by using $\mathrm{R}$ software hierarchical clustering analysis method. The results showed no direct impact between the contents of gallic acid and ellagic acid in $E$. angustifolia L. leaves and their origins. Moreover, E. angustifolia $\mathrm{L}$. Trees are mostly distributed in southern Xinjiang, and the climate difference between the north and the south is large; therefore, the contents of gallic acid and ellagic acid should be different. However, the difference was not significant. The reason for this phenomenon may be that the varieties of $E$. angustifolia L. in the north and south were consistent, and that the harvest time was similar. Comparing the contents of gallic acid and ellagic acid of E. angustifolia L. leaves that were harvested in different months, the best collection time was shown to be July. However, considering the serious damage in plants in July, from a comprehensive consideration of medicinal value and economy, we recommend October as the best period for harvesting leaves. In Xinjiang, the temperature from January to March is still low. Therefore, the leaves of E. angustifolia L. trees in Xinjiang begin to germinate at the end of March, and completely grow out in May. By the end of November, the leaves are basically withered. Therefore, this experiment began to pick the leaves from May until analyzed the components content changes. In May, the trees just grow new leaves, and the leaves in July are sufficient with nutrients. In August and September, the trees begin to supply nutrients to the fruits; thus, the leaves contain low nutrients. The leaf nutrients begin to slow in October and November. Therefore, from May to November, the changes in gallic acid and ellagic acid in the leaves of E. angustifolia L. can reflect the life process of leaves from new growth to wilting, and these changes are related to the environment, climate, site conditions, and different varieties.

\section{CONCLUSION}

In this study, HPLC method was used to determine the contents of gallic acid and ellagic acid in the water-extracted parts of 10 batches of E. angustifolia L. harvested from different origins. The results showed differences in the contents of gallic acid and ellagic acid in the leaves harvested from different origins. The dynamic changes of gallic acid and ellagic acid in the water-extracted parts of E. angustifolia L. leaves were used to provide experimental basis for determining the picking time of E. angustifolia L. leaves. Therefore, the method is accurate, rapid and, sensitive, and provides theoretical basis for research, quality control, development, and utilization of E. angustifolia L. leaves.

\section{ACKNOWLEDGMENT}

This work was supported by the National Natural Science Foundation of China (grant No.: 81860772) and the Xinjiang Science and Technology Fund (Grant numbers 2015211C025). 


\section{REFERENCE}

1. SATCM. Chinese Materia Medica; Shanghai Science and Technology Press: Shanghai, 1999; Vol. 5, 428-234.

2. Shilin, C.; Yulin, L. Chinese Herbal Medicine; Academy of Military Medical Sciences Press: Beijing, 2006, p 226.

3. Weiwei, Y.; Guorong, Y. Resources and research status of Elaeagnus angustifolia L. J. Tianjin Agric. Univ. 2000, 16, 46-9.

4. Yanwei, X. Development and utilization of Elaeagnus angustifolia L. Anhui Agric. Sci. 2007, 35, 399-400.

5. Lijun, G.; Yutao, W. Characteristics and utilization value of germplasm resources of Elaeagnus angustifolia L. Chin. Wild Plant Resour. 2008, 27, 32-4.

6. Suyalatu, H. Feeding nutritional value of deciduous leaves. Feed Res. 2004, 11, 26-7.

7. Hui, T.; Yanjun, L.; Mei, L. Study on antioxidation of water decoction extracts from leaves of Elaeagnus angustifolia L. J. Shihezi Univ. (Nat. Sci. Ed.) 2010, 28, 207-10.

8. Binsheng, W.; Hengyi, Q.; Ma, J.; Xiling, S.; Dong, W.; Qiusheng, Z. Protective effects of Elaeagnus angustifolia leaf extract against myocardial ischemia/reperfusion injury in isolated rat heart. $J$. Chem. 2014, 2014, 6796-802.

9. Honglin, T.; Haiyan, G.; Yi, F. Effects of extracts from Xinjiang jujube leaves on blood glucose in diabetic mice. Hubei Agric. Sci. 2017, 56, 103-6.

10. Xing, W.; Na, Z.; Yingli, M. Determination of gallic acid in Rhizoma Bergenia scopulosa: from different producing areas by HPLC. Anhui Agric. Sci. 2014, 42, 1276-8.
11. Lei, Z.; Jintian, L.; Tongwen, W.; Lina, L. Simultaneous determination of four flavonoid aglycone analogs in the inflorescence of Juglans Regia L. by high-performance liquid chromatography-diode array detection. J. Liq. Chromatogr. Relat. Technol. 2013, 36, 1986-98.

12. Zhiguo, J.; Ruicheng, S.; Haide, Z.; Yongcheng, L. Separation and purification of antioxidant glycoglycerolipids from fruit of cucurbita moschata by high-speed counter-current chrmatography coupled with preparative high-performance liquid chromatography. J. Liq. Chromatogr. Relat. Technol. 2014, 37, 974-87.

13. Kui, C.; Songxia, Y.; Yinyin, C.; Qualitative study on chemical constituents of Elaeagnus angustifolia pulp. Anhui Agric. Sci. 2015, 24, 209-11.

14. Xiaorong, W.; Shuonan, W., Weiwei, L. Analysis of chemical constituents in leaves of Elaeagnus angustifolia L. Shaanxi Agric. Sci. 2013, 59(1), 66-8.

15. Shasha, T.; Xiaoying, Z.; Haonan, Y.; Yun, S. Determining three kinds of organic acids in the leaves of Elaeagnus angustifolia $\mathrm{L}$. From different regions and different growth stages in Xinjiang province by using high-performance thin-layer chromatography. $J$. Planar Chromatogr. 2019, 32(2), 115-20.

16. Bayiertai; Zhiyin, Y.; Tong-tong, G.; Yun, S. Determination of trace elements and principal components analysis in Elaeagnus angustifolia L. leaves from different growing Areas of Xinjiang. Chem. Reagents 2017, 39(3), 271-5.

17. Shamisbanu, A.; Bayertai; Yun, S.; Identification and chemical constituents of Elaeagnus angustifolia leaves in Xinjiang. J. Xinjiang Med. Univ. 2019, 42(4), 529-32, 540. 